Klinische zorg rondom de vaatpatiënt 


\section{Klinische zorg rondom de vaatpatiënt}

onder redactie van

P. Kitslaar

M. Lemson

C. Schreurs

H. Bergs

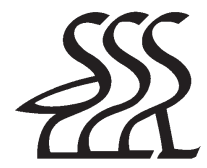

Bohn Stafleu van Loghum

Houten 2007 
(C) Bohn Stafleu van Loghum, 2007

Alle rechten voorbehouden. Niets uit deze uitgave mag worden verveelvoudigd, opgeslagen in een geautomatiseerd gegevensbestand, of openbaar gemaakt, in enige vorm of op enige wijze, hetzij elektronisch, mechanisch, door fotokopieën of opnamen, hetzij op enige andere manier, zonder voorafgaande schriftelijke toestemming van de uitgever.

Voor zover het maken van kopieën uit deze uitgave is toegestaan op grond van artikel 16b Auteurswet $1912 \mathrm{j}^{\mathrm{O}}$ het Besluit van 20 juni 1974, Stb. 351, zoals gewijzigd bij het Besluit van 23 augustus 1985, Stb. 471 en artikel 17 Auteurswet 1912, dient men de daarvoor wettelijk verschuldigde vergoedingen te voldoen aan de Stichting Reprorecht (Postbus 3051, $2130 \mathrm{~KB}$ Hoofddorp). Voor het overnemen van (een) gedeelte(n) uit deze uitgave in bloemlezingen, readers en andere compilatiewerken (artikel 16 Auteurswet 1912) dient men zich tot de uitgever te wenden.

Samensteller(s) en uitgever zijn zich volledig bewust van hun taak een betrouwbare uitgave te verzorgen. Niettemin kunnen zij geen aansprakelijkheid aanvaarden voor drukfouten en andere onjuistheden die eventueel in deze uitgave voorkomen.

ISBN 9789031348329

NUR 897

Ontwerp omslag: Boekhorst Design, Culemborg Ontwerp binnenwerk: TEFF Typography Automatische opmaak: Pre Press, Zeist

Met dank aan $\frac{\text { NV VASCUTEKK voor: }}{\text { TERUMO }}$

figuren $6.1,6.2,6.3,6.6,6.7,6.8,6.9,7.3,7.7$

Bohn Stafleu van Loghum

Het Spoor 2

Postbus 246

3990 GA Houten

www.bsl.nl 


\section{Woord vooraf}

De behandeling van hart- en vaatziekten, nog steeds doodsoorzaak nummer één in Nederland, richt zich primair op vermindering van risicofactoren. Een groot aantal vaatpatiënten zal in de loop van hun ziekteproces, naast medicamenteuze behandelingen, ook radiologische interventies, vaatoperaties, of combinaties van beide ondergaan.

De zorg voor vaatpatiënten laat de laatste twee decennia markante veranderingen zien. Allereerst hebben zich fascinerende technische ontwikkelingen voorgedaan in zowel de diagnostiek als de behandeling van patiënten met vaatziekten. Voorbeelden hiervan zijn de MRA en de CTA, de magnetische resonantie en de computertomografische angiografie, en endovasculaire operaties. Daarnaast worden vaatpatiënten steeds vaker behandeld door multidisciplinaire teams, bestaande uit medisch specialisten van verschillende disciplines en beroepsbeoefenaars met een verpleegkundige achtergrond. Deze aanpak verschilt van de eerder gebruikelijke disciplinegeoriënteerde aandacht voor afzonderlijke onderdelen van het circulatiesysteem, waarbij bijvoorbeeld patiënten met perifere vaatziekten alleen de aandacht kregen van de chirurgen. Chirurgen op hun beurt vonden aandacht voor risicofactoren voor vaatziekten meer 'iets voor de internist'. Tegenwoordig richten steeds meer ziekenhuizen gespecialiseerde verpleegafdelingen in voor vaatpatiënten, meestal beginnend met aparte vaatchirurgische afdelingen. In lijn hiermee ontstaan er nieuwe rollen voor gespecialiseerde verpleegkundigen en worden taken van artsen overgenomen door nieuwe categorieën beroepsbeoefenaars, zoals 'nurse practitioners' en 'physician assistants'.

Deze ontwikkelingen vonden tot nu toe nog niet hun weerslag in een Nederlandstalig handboek of leerboek. Nederlandstalige tekstboeken over vasculaire geneeskunde en zelfs de recentste Nederlandstalige chirurgische leerboeken besteden relatief weinig aandacht aan de specifieke diagnostiek en behandeling van vaatchirurgische patiënten en vasculaire interventies. In deze leemte hopen wij te voorzien met dit boek, dat de zorg voor patiënten met arteriële en veneuze vaatziekten in het ziekenhuis belicht vanuit zowel een medisch als een verpleegkundig oogpunt.

Er is gekozen voor een encyclopedische opzet van het boek met aparte hoofdstukken en secties voor iedere categorie vaatpatiënten. Dit vergemak- 
kelijkt het terugvinden van informatie voor diegenen die in direct contact met deze patiënten worden verondersteld te kunnen ingaan op hun vragen over diagnostiek of interventies. Om die reden zijn ook de beschrijvingen van de vaatchirurgische en radiologische interventies van een zodanige diepgang, dat de lezer na raadpleging ervan ook technische vragen van de patiënt professioneel kan beantwoorden. Het boek is primair geschreven voor een doelgroep van gespecialiseerde verpleegkundigen, vasculaire nurse practitioners en physician assistants. Daarom bevat het boek een apart hoofdstuk over verpleegkundige aspecten van patiënten met vaataandoeningen en worden alle secties over specifieke vaatziekten afgesloten met een puntsgewijze samenvatting van verpleegkundige aspecten. Ook beginnen die hoofdstukken met een casusbeschrijving, die kan dienen als uitgangspunt voor een probleemgestuurde didactische toepassing van dat hoofdstuk. De centrale rol die de bloedstolling en de verschillende vasculaire tests en afbeeldingtechnieken spelen bij vaatziekten rechtvaardigden daaraan gewijde aparte hoofdstukken. Hetzelfde geldt voor het toenemende belang van de vasculaire interne geneeskunde en pijnbestrijdingtechnieken bij de behandeling van vaatpatiënten. Eén hoofdstuk beschrijft alle vaatziekten systematisch samenvattend. In een ander hoofdstuk wordt de anatomie van het circulatiesysteem vanuit het perspectief van de verschillende vaatchirurgische en radiologische interventies beschreven. Verder is daarin een korte sectie opgenomen over de principes die ten grondslag liggen aan de verschillende in het boek besproken functietesten van de bloedsomloop.

Bij het samenstellen van het boek had de redactie naast de primaire doelgroep zeker ook andere potentiële lezers voor ogen, die mee verantwoordelijk zijn voor de directe zorg voor klinische vaatpatiënten. Dit zijn vooral laboranten op vaatfunctielaboratoria en angiografiekamers. Ook medische studenten en beginnende arts-assistenten die hun stages doen op vaatchirurgische afdelingen kunnen het boek, geschreven door deskundigen uit de praktijk, gebruiken als informatiebron voor hun klinische werkzaamheden.

Het boek is het resultaat van de inspanningen van een heel scala aan deskundigen: vaatchirurgen, internisten, radiologen en een revalidatiearts, anesthesisten, laboranten van de afdeling klinische neurofysiologie en het vaatfunctielaboratorium en verpleegkundigen van de afdeling vaatchirurgie. Hun namen zijn vermeld in de lijst van auteurs. De redactie is hun grote dank verschuldigd voor hun deskundige bijdragen aan dit boek. Daarnaast bedanken we Mirthe Wishaupt, verpleegkundige van de afdeling Vaatchirurgie van het azM, en Mies Renckens, praktijkdocente Verpleegkundig Onderwijs en Training van het azM, die fungeerden als lezers-testpanel, voor hun moeite en hun waardevolle suggesties.

De redactie hoopt dat dit boek zal bijdragen aan een verdere professionalisering van al die medische en paramedische beroepsbeoefenaars en degenen die daarvoor in opleiding zijn, die samen verantwoordelijk zijn voor een zo goed mogelijke klinische zorg voor de vaatpatiënt. 


\section{Inhoud}

\section{Woord vooraf}

Personalia

XVII

1 Anatomie en fysiologie van het vaatstelsel $\quad 1$

1.1 Inleiding

1.2 Anatomie

1.2.1 Het arteriële systeem (figuur 1.1)

1.2.2 Het veneuze systeem

1.2.3 Anatomische varianten van het arteriële en veneuze systeem

1.3 Fysiologie van het vaatstelsel

1.3.1 Opbouw van de bloedvaten

1.3.2 Fysiologie en pathofysiologie van het arteriële systeem

1.3.3 Fysiologie en pathofysiologie van de microcirculatie

1.3.4 Fysiologie en pathofysiologie van het veneuze systeem

2 Hemostase

2.1 Hemostase

2.2 Afwijkingen in de hemostase

2.2.1 Trombocytopenie

2.2.2 Afwijkingen in de fibrinevorming 19

2.2.3 Verhoogde tromboseneiging

2.3 Geneesmiddelen die aangrijpen op de hemostase

2.3.1 Trombocytenaggregatieremmers

2.3.2 Cumarinen

2.3.3 Heparines

2.3.4 Trombolytica 
$\begin{array}{lll}\text { 2.3.5 } & \text { Hemostatica } & 22 \\ \text { 2.3.6 } & \text { Bloedproducten } & 23 \\ \text { 2.4 } & \text { Bloedonderzoek naar stolling } & 23\end{array}$

3 Overzicht van vaataandoeningen 25

3.1 Inleiding 25

3.2 Atherosclerose 26

3.2.1 Inleiding 26

3.2.2 Pathologie 26

3.2.3 Klinische effecten, diagnostiek en behandeling 28

3.3 Auto-immuunvaatziekten 29

3.3.1 Inleiding 29

3.3.2 Primaire vasculitiden 29

3.3.3 Secundaire vasculitiden 33

3.4 Bindweefselziekten 34

3.5 Ziekte van Raynaud 34

4 Verpleegkundige aspecten van vaatlijden gerelateerd aan de elf gezondheidspatronen van Marjorie Gordon

$\begin{array}{lll}4.1 & \text { Inleiding } & 37\end{array}$

4.2 Beleving en instandhouding van de gezondheid 37

4.2.1 Kennis van de aandoening 37

4.2.2 Informatie over de postoperatieve beperkingen 38

4.2.3 Leefstijl- en gezondheidsvoorlichting 39

4.2.4 Therapietrouw 39

4.3 Voeding en stofwisseling 39

4.3.1 Gewichtsproblemen $\quad 39$

4.3.2 Gezonde voeding 40

4.3.3 Preventie en behandeling van ondervoeding 41

4.3.4 Parenteraal vochtbeleid 41

4.3.5 Vitale functies 42

4.3.6 Preoperatief nuchter blijven 43

4.3.7 Prehydreren 43

4.3.8 Wondgenezing en huidproblemen 44

4.3.9 Decubitus 44

4.4 Uitscheiding $\quad 45$

4.5 Activiteiten 45

4.5.1 Mobiliteit 45

4.5.2 Verminderd ademhalingsvermogen 46

4.5.3 Vermoeidheid 46

4.5.4 Beperkingen gerelateerd aan de operatie 46

4.6 Slaap en rust 46

4.7 Waarneming/cognitie 47

4.8 Zelfbeleving $\quad 47$ 
4.8.1 Verdriet, somberheid en angst 47

4.8.2 Depressie 48

4.8.3 Verstoord zelfbeeld 48

4.8.4 Schuldgevoel 48

4.9 Rollen en relaties 48

4.9.1 Gezinsstructuur 48

4.9.2 Arbeidsproces 48

4.9.3 Sociale beperkingen; sport en ontspanning 48

4.10 Seksualiteit 49

4.11 Stressverwerking 49

4.12 Levensovertuiging en waarden 49

4.13 Tot slot 49

5 Diagnostiek $\quad \mathbf{5 1}$

5.1 Inleiding 51

5.2 Doppleronderzoek 52

5.2.1 Techniek van het doppleronderzoek 52

5.2.2 Doppleronderzoek van de bovenste extremi-

5.2.3 Doppleronderzoek van de onderste extremiteiten 54

5.2.4 Doppleronderzoek van de intracraniële hersenarteriën: transcraniaal doppleronderzoek (TCD) 55

5.3 Duplexonderzoek 56

5.3.1 Techniek van het duplexonderzoek 56

5.3.2 Duplexonderzoek van de carotiden en vertebrale arteriën 57

5.3.3 Duplexonderzoek van de abdominale arteriën 58

5.3.4 Duplexonderzoek van een perifere bypass 58

5.3.5 Duplexonderzoek van a. femoralis superficialis, poplitea en crurale arteriën

5.3.6 Duplexonderzoek van het veneuze systeem van de onderste extremiteit

5.3.7 Pre-shunt duplexonderzoek van de bovenste extremiteit

5.3.8 Duplexonderzoek van een dialyseshunt 60

5.3.9 Beperkingen van duplexonderzoek 60

5.4 Meting van de transcutane zuurstofspanning $\left(\mathrm{tcPO}_{2}\right)$

5.5 Magnetische resonantieangiografie (MRA) 61

5.5.1 Indicaties 61

5.5.2 Techniek 62

5.5.3 Uitvoering 63

5.5.4 Contra-indicaties 64

5.6 Computertomografische angiografie (CTA) 65 


$\begin{array}{lll}\text { 5.6.1 } & \text { Indicaties } & 65 \\ \text { 5.6.2 } & \text { Techniek } & 65 \\ 5.6 .3 & \text { Uitvoering } & 65 \\ 5.6 .4 & \text { Beperkingen } & 68 \\ 5.7 & \text { Intra-arteriële digitale subtractieangiografie (ia- } & \\ & \text { DSA) } & 69 \\ 5.7 .1 & \text { Indicaties } & 69 \\ 5.7 .2 & \text { Techniek } & 70 \\ 5.7 .3 & \text { Uitvoering } & 71 \\ 5.7 .4 & \text { Contra-indicaties } & 74 \\ 5.7 .5 & \text { Beperkingen } & 74 \\ 5.8 & \text { Flebografie } & 74 \\ 5.8 .1 & \text { Indicaties } & 74 \\ 5.8 .2 & \text { Techniek } & 75 \\ 5.8 .3 & \text { Uitvoering } & 77 \\ 5.8 .4 & \text { Contra-indicaties } & 77 \\ 5.9 & \text { Elektro-encefalografie (EEG) } & 77 \\ 5.9 .1 & \text { Indicatie } & 77 \\ 5.9 .2 & \text { Techniek } & 78 \\ 5.9 .3 & \text { Uitvoering } & 78 \\ 5.9 .4 & \text { Beperkingen } & 78 \\ 5.10 & \text { Motor-evoked potentials (MEP) monitoring bij } & \\ & \text { thoracoabdominale aneurysma chirurgie } & 78 \\ 5.10 .1 & \text { Indicatie } & 78 \\ 5.10 .2 & \text { Techniek } & 79 \\ 5.10 .3 & \text { Uitvoering } & 79 \\ 5.11 & \text { Specifieke verpleegkundige aspecten van beeld- } & \\ & \text { vormende diagnostiek } & 80 \\ 5.12 & \text { Tot slot } & \end{array}$

6 Occlusief vaatlijden $\quad 83$

$6.1 \quad$ Obstructief perifeer arterieel vaatlijden 83

6.1.1 Inleiding 83

6.1.2 Diagnostiek van patiënten met PAV 84

6.1.3 Behandeling van patiënten met PAV 87

6.1.4 Follow-up 95

6.2 Obstructief visceraal vaatlijden 97

6.2.1 Inleiding 98

6.2.2 Acute mesenteriële ischemie 98

6.2.3 Chronische mesenteriële ischemie 101

6.3 Cerebrovasculair obstructief vaatlijden 103

6.3.1 Inleiding 103

6.3.2 Klinische presentatie 104

$\begin{array}{ll}\text { 6.3.3 Diagnostiek } & 104\end{array}$

$\begin{array}{lll}\text { 6.3.4 Behandeling } & 104\end{array}$ 
6.3.5 Complicaties 109

6.3.6 Prognose 110

6.4 Compressie- of entrapmentsyndromen 111

6.4.1 Inleiding 111

6.4.2 Klinische presentatie 113

6.4.3 Diagnostiek 113

6.4.4 Behandeling 114

6.4.5 Follow-up 115

6.5 Acute perifere ischemie en arteriële embolie 115

6.5.1 Inleiding 116

6.5.2 Klinische presentatie 116

6.5.3 Diagnostiek 116

$\begin{array}{ll}\text { 6.5.4 Behandeling } & 117\end{array}$

6.5.5 Compartimentsyndroom 120

6.5.6 Prognose 120

6.6 Diabetische voet 121

6.6.1 Inleiding 121

6.6.2 Ontstaan van het voetulcus 122

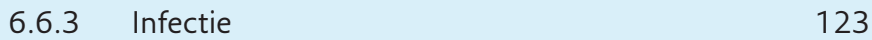

6.6.4 Diagnostiek 123

6.6.5 Behandeling 124

$\begin{array}{lll}\text { 6.6.6 Follow-up } & 125\end{array}$

7 Aneurysmatisch vaatlijden 127

$\begin{array}{lll}7.1 & 127\end{array}$

7.2 Aneurysma van de infrarenale aorta 128

$\begin{array}{lll}7.2 .1 & \text { Inleiding } & 128\end{array}$

7.2.2 Klinische presentatie 129

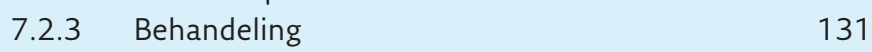

$\begin{array}{lll}7.2 .4 & \text { Techniek } & 132\end{array}$

7.2.5 Complicaties 136

$\begin{array}{lll}7.2 .6 & \text { Prognose } & 137\end{array}$

7.3 Geruptureerd aneurysma van de abdominale aorta 138

$\begin{array}{lll}7.3 .1 & \text { Inleiding } & 138\end{array}$

7.3.2 Klinische presentatie 139

$\begin{array}{ll}7.3 .3 & \text { Diagnostiek } \\ 7.3 .49\end{array}$

$\begin{array}{lll}\text { 7.3.4 Behandeling } & 140\end{array}$

7.3.5 Complicaties 141

$\begin{array}{lll}\text { 7.3.6 Prognose } & 141\end{array}$

7.4 Aneurysma van de thoracale en thoracoabdominale aorta 142

$\begin{array}{lll}7.4 .1 & \text { Inleiding } & 142\end{array}$

$\begin{array}{ll}7.4 .2 & \text { Diagnostiek } \\ 7.4 .3 & 142\end{array}$

$\begin{array}{lll}\text { 7.4.3 Behandeling } & 144\end{array}$ 
7.4.4 Per- en postoperatieve complicaties

7.4.5 Follow-up

7.5 Dissectie van de aorta

7.5.1 Inleiding

7.5.2 Diagnostiek

7.5.3 Behandeling

7.5.4 Follow-up

7.6 Arteria-femoralisaneurysma

7.6.1 Inleiding

155

7.6.2 Klinische presentatie

7.6.3 Behandeling

7.7 Arteria-poplitea-aneurysma

7.7.1 Inleiding

7.7.2 Klinische presentatie

7.7.3 Behandeling

7.8 Pseudoaneurysmata

7.9 Overige aneurysmata

8 Vasculair trauma

8.1 Inleiding 161

8.2 Vaatletsel in de thorax 162

8.3 Vaatletsel in de buik 162

8.4 Vaatletsel aan de extremiteiten 163

9 Veneus systeem $\quad 165$

9.1 Inleiding 165

9.1.1 Veneuze pathologie 165

9.1.2 Diagnostiek 166

9.1.3 Behandeling 167

9.2 Varicosis 169

9.2.1 Diagnostiek 169

9.2.2 Behandeling 170

9.2.3 Complicaties 170

9.2.4 Follow-up 171

9.3 Chronische veneuze insufficiëntie (CVI) 171

9.3.1 Diagnostiek 171

$\begin{array}{ll}\text { 9.3.2 Behandeling } & 172\end{array}$

9.3.3 Follow-up 173

9.4 Diepe veneuze trombose (DVT) 173

9.4.1 Complicaties 174

9.4.2 Diagnostiek 174

9.4.3 Behandeling 175

9.4.4 Follow-up 175

9.5 Overige veneuze aandoeningen 175 
9.5.1 Diepe veneuze trombose van de bovenste extremiteit

9.5.2 Tromboflebitis

9.5.3 Veneuze tumoren

10 Vaattoegangschirurgie

179

10.1 Inleiding

179

10.2 Diagnostiek/preoperatief onderzoek

10.2.1 Centraalveneuze katheter

180

10.2.2 Arterioveneuze fistel

10.3 Soorten toegang tot de bloedbaan

10.3.1 Centraalveneuze katheters

10.3.2 Port-A-Cath

10.3.3 Inwendige toegang of AV-fistel

10.4 Rijping van een AV-fistel

10.5 Complicaties van AV-fistels

10.5.1 Postoperatieve complicaties

10.5.2 Late complicaties

10.6 Nabehandeling

10.6.1 Centraalveneuze katheters

10.6.2 AV-fistel

\section{Amputaties}

11.1 Inleiding

11.2 Principes van amputatie

11.3 Acute amputatie

11.4 Electieve amputatie

11.5 Bepalen van het niveau van amputatie

11.5.1 De chirurg

11.5.2 De revalidatiearts

11.6 Niveaus van amputatie (figuur 11.1) 196

11.7 Postoperatieve fase 198

11.7.1 Kleine amputaties 198

11.7.2 Grote amputaties $\quad 199$

11.7.3 Complicaties 201

11.7.4 Selectie van vervolgtraject 202

11.8 Fase na klinisch ontslag uit ziekenhuis 203

11.9 Follow-up 204

12 Vasculaire geneeskunde 207

$\begin{array}{lll}12.1 & \text { Inleiding } & 207\end{array}$

12.2 Niet-modificeerbare risicofactoren voor hart- en vaatziekten 209

12.2.1 Leeftijd 209

12.2.2 Geslacht 209 
12.2.3 Al aanwezige vaatschade 210

12.2.4 Belaste familieanamnese (genetische factoren) 210

12.3 Modificeerbare risicofactoren voor hart- en vaatziekten 210

12.3.1 Roken 210

12.3.2 Voeding 211

12.3.3 Overgewicht 211

12.3.4 Hypertensie 211

12.3.5 Hypercholesterolemie 212

12.3.6 Diabetes mellitus type 2

12.3.7 Microalbuminurie 213

12.4 Behandeling van risicofactoren 213

12.4.1 Leefstijladviezen 213

12.4.2 Medicamenteuze behandelingen 214

12.4.3 Specifieke behandeling van enkele belangrijke risicofactoren 214

$\begin{array}{lll}12.4 .4 & \text { Antitrombotica } & 217\end{array}$

13 Pijnbestrijding bij vaatchirurgische patiënten 219

$\begin{array}{lll}13.1 & \text { Inleiding } 219\end{array}$

13.2 Algemene principes van pijn en pijnbestrijding 220

13.3 Pijnmeting 223

13.4 Postoperatieve pijn en postoperatieve pijnbestrijding 225

13.5 Fantoompijn 227

13.6 Chronische pijn en pijnbestrijding bij onbehandelde of onbehandelbare kritieke ischemie $\quad 227$

$\begin{array}{lll}13.7 & 229\end{array}$

13.8 Bijzondere toedieningswegen voor analgetica in de vaatchirurgische praktijk 230

13.8.1 Patiëntgecontroleerde analgesie (PCA) 230

13.8.2 Epidurale pijnbestrijding 231

13.8.3 Spinal cord stimulation (SCS) 232

13.9 Organisatie van de klinische pijnbehandeling 232

\section{Literatuur}

Websites

Ingrepen

Kompassen

Stoppen met roken 238

Patiënteninformatie en patiëntenverenigingen 238

Richtlijnen 238

Wetenschappelijke sites $\quad 239$

Beroepsverenigingen 239 
Risicocalculators

Overig

Afkortingen en verklarende woordenlijst 243

Medicatie 255

Register 259 


\section{Personalia}

\section{De redactie}

Prof. dr. P.J.E.H.M. Kitslaar, chirurg/vaatchirurg Academisch Ziekenhuis Maastricht Afdeling Heelkunde

Mw. dr. M.S. Lemson, chirurg/vaatchirurg Slingeland Ziekenhuis, Doetinchem Afdeling Chirurgie

Mw. C.W.M. Schreurs, Physician Assistant i.o. Academisch Ziekenhuis Maastricht Afdeling Heelkunde

Mw. drs. H.M.E. Bergs, verpleegkundige Academisch Ziekenhuis Maastricht Afdeling Heelkunde

\section{Auteurs}

Hoofdstuk 1: Anatomie en fysiologie van het vaatstelsel Mw. dr. M.S. Lemson, chirurg/vaatchirurg, Slingeland Ziekenhuis Doetinchem, Afdeling Chirurgie

Hoofdstuk 2: Hemostase

Mw. dr. M.S. Lemson, chirurg/vaatchirurg, Slingeland Ziekenhuis Doetinchem, Afdeling Chirurgie

Hoofdstuk 3: Overzicht van vaataandoeningen

Dr. R.J.M.W. Rennenberg, internist/vasculair geneeskundige, Academisch Ziekenhuis Maastricht, Afdeling Interne Geneeskunde 
Hoofdstuk 4: Verpleegproblemen bij patiënten met vaatlijden

Mw. C.W.M. Schreurs, Physician Assistant i.o., Academisch Ziekenhuis Maastricht, Afdeling Heelkunde

Hoofdstuk 5: Diagnostiek

Dr. M.W. de Haan, interventieradioloog, Academisch Ziekenhuis Maastricht, Afdeling Radiologie, (paragrafen 5.5, 5.6, 5.7, 5.8)

Mw. M.J.H. de Laat, vasculair-diagnostisch laborante, Academisch Ziekenhuis Maastricht, Afdeling Heelkunde, (paragrafen 5.2, 5.3, 5.4)

Mw. A.M.J. Neven-Plaum, vasculair-diagnostisch laborante, Academisch Ziekenhuis Maastricht, Afdeling Heelkunde, (paragrafen 5.2, 5.3, 5.4)

Dhr. G. Nöthen, laborant klinische neurofysiologie, Academisch Ziekenhuis Maastricht, Afdeling Neurologie, (paragrafen 5.2.4 Transcranieel Doppler onderzoek (TCD), 5.9)

Dr. R.J. Nijenhuis, arts-assistent chirurgie, Maasland Ziekenhuis Sittard, Afdeling Chirurgie, (paragrafen 5.5, 5.6, 5.7, 5.8)

Mw. C.W.M. Schreurs, Physician Assistant i.o., Academisch Ziekenhuis Maastricht, Afdeling Heelkunde, (verpleegkundige aspecten)

Dhr. M. Sleijpen, laborant klinische neurofysiologie, Academisch Ziekenhuis Maastricht, Afdeling Neurologie, (paragraaf 5.10)

Hoofdstuk 6: Occlusief vaatlijden

Mw. dr. M.S.P. Huijberts, internist/endocrinoloog, Academisch Ziekenhuis Maastricht, Afdeling Interne Geneeskunde, (paragraaf 6.6)

Prof. dr. P.J.E.H.M. Kitslaar, chirurg/vaatchirurg, Academisch Ziekenhuis Maastricht, Afdeling Heelkunde, (paragrafen 6.1, 6.4)

Prof dr. N.C. Schaper, internist/endocrinoloog, Academisch Ziekenhuis Maastricht, Afdeling Interne Geneeskunde, (paragraaf 6.6)

Mw. C.W.M. Schreurs, Physician Assistant i.o., Academisch Ziekenhuis Maastricht, Afdeling Heelkunde, (verpleegkundige aspecten)

Dr. J.H.M. Tordoir, chirurg/vaatchirurg, Academisch Ziekenhuis Maastricht, Afdeling Heelkunde, (paragraaf 6.5)

Drs. J.L. van Wanroij, chirurg/vaatchirurg, Academisch Ziekenhuis Maastricht, Afdeling Heelkunde, (paragrafen 6.2, 6.3)

Hoofdstuk 7: Aneurysmatisch vaatlijden

Prof. dr. M.J.H.M. Jacobs, chirurg/vaatchirurg, Academisch Ziekenhuis Maastricht, Afdeling Heelkunde, (paragrafen 7.4, 7.5)

Mw. C.W.M. Schreurs, Physician Assistant i.o., Academisch Ziekenhuis Maastricht, Afdeling Heelkunde, (verpleegkundige aspecten)

Dr. G.W.H. Schurink, chirurg/vaatchirurg, Academisch Ziekenhuis Maastricht, Afdeling Heelkunde, (paragrafen 7.1, 7.2, 7.3, 7.6, 7.7, 7.8, 7.9)

Hoofdstuk 8: Vasculair trauma

Dr. G.W.H. Schurink, chirurg/vaatchirurg, Academisch Ziekenhuis Maastricht, Afdeling Heelkunde 
Hoofdstuk 9: Veneus systeem

Prof. dr. P.J.E.H.M. Kitslaar, chirurg/vaatchirurg, Academisch Ziekenhuis Maastricht, Afdeling Heelkunde

Mw. C.W.M. Schreurs, Physician Assistant i.o., Academisch Ziekenhuis Maastricht, Afdeling Heelkunde, (verpleegkundige aspecten)

Hoofdstuk 10: Vaattoegangschirurgie

Mw. dr. M.S. Lemson, chirurg/vaatchirurg, Slingeland Ziekenhuis Doetinchem, Afdeling Chirurgie

Dr. J.H.M Tordoir, chirurg/vaatchirurg, Academisch Ziekenhuis Maastricht, Afdeling Heelkunde

Mw. C.W.M. Schreurs, Physician Assistant i.o., Academisch Ziekenhuis Maastricht, Afdeling Heelkunde, (verpleegkundige aspecten)

Hoofdstuk 11: Amputaties

Mw. dr. M.S. Lemson, chirurg/vaatchirurg, Slingeland Ziekenhuis Doetinchem, Afdeling Chirurgie

Dr. A.P. Sanders, revalidatiearts, Academisch Ziekenhuis Maastricht, Afdeling Revalidatie

Mw. C.W.M. Schreurs, Physician Assistant i.o., Academisch Ziekenhuis Maastricht, Afdeling Heelkunde, (verpleegkundige aspecten)

Hoofdstuk 12: Vasculaire geneeskunde

Dr. R.J.M.W. Rennenberg, internist/vasculair geneeskundige, Academisch Ziekenhuis Maastricht, Afdeling Interne Geneeskunde

Hoofdstuk 13: Pijnbestrijding bij vaatchirurgische patiënten

Drs. H.F. Gramke, anesthesioloog, Academisch Ziekenhuis Maastricht, Afdeling Anesthesiologie

Prof. dr. A.E. Martens, anesthesioloog, Academisch Ziekenhuis Maastricht, Afdeling Anesthesiologie

Drs. J.W. Ruys, arts-assistent anesthesiologie, Academisch Ziekenhuis Maastricht, Afdeling Anesthesiologie 